\title{
ART AND RELIGION AS INVITATION. AN EXPLORATION BASED ON JOHN DEWEY'S THEORY OF EXPERIENCE AND IMAGINATION
}

\author{
HANS ALMA*
}

Free University, Brussels

\begin{abstract}
In this essay, the relation between art and religion is explored using the concepts experience and imagination as understood by the American philosopher John Dewey. In Dewey's view, experience involves both the experiencer and the experienced: it is a phenomenon of the in-between. When we are really touched by what we meet in interacting with our physical and social surroundings, experience acquires an aesthetic quality that opens us to the value and the potential of what we perceive. We can see the factual in light of the possible, thus enriching it with new layers of meaning. We experience this as resonance between us and the world. It is the work of the imagination. Due to their imaginative capacity, humans can aspire to a 'good life'. This aspiration is discussed in terms of invitation and response. Can we experience ourselves as being invited to respond to this unruly world with attachment and care? Here art and religion come into play. Art is understood as the domain of the possible: it explores the world behind or beyond what we usually accept as fact. An aesthetic experience acquires religious quality when it evokes in us an ideal that guides our sense of self and world, stimulating us to realize our ideals in daily actions. If inspired by imagination, art and religion may evoke intense experiences of resonance and invite us to new ways of connecting and transformative action. This is explored with the help of a hermeneutical circle, a 'cycle of imagination'.
\end{abstract}

KEYWORDS: experience, imagination, resonance, invitation, response

My view on art and religion is strongly influenced by the pragmatism of John Dewey (1859-1952), especially in his books Art as Experience (1934/1989) and A Common Faith (1934). Dewey's philosophy takes its point of departure in human experience as it occurs within the context of the relationships between people and their surrounding world. Art helps people to perceive this world in new ways, and religion helps them to collaborate with others in realizing a shared ideal. Both in art and religion, the imagination is of pivotal importance. In this article, I shall first explore Dewey's use of the concepts experience and imagination. Next, I shall discuss his

* HANS ALMA (PhD 1998, Free University, Amsterdam) is guest professor in Contemporary Humanism, Faculty of Arts and Philosophy, Free University, Brussels (VUB). Email: hendrikjen.alma@vub.be. 
thoughts on art and religion respectively. I relate his views to key ideas of the political philosopher William Connolly on 'a world of becoming' and to the idea of 'resonance' as developed by the sociologist Hartmut Rosa. This results in a relational conception of art and religion with invitation and response as crucial elements.

\section{Experience}

Dewey situates experience within the interaction or rather transaction of a person with his social and physical surroundings. Both person and environment contribute to the experience as it develops within this transaction and both are transformed through the experience. Physical things and social events are transformed by entering a human context and acquiring new meanings. The person changes by coping with things and events of which s/he was previously unaware. In Dewey's view, experience is not primarily an internal, mental phenomenon. Experience involves both the experiencer and the experienced: it is a phenomenon of the in-between.

In interacting with our physical and social surroundings, much depends on the quality of our perception. With perception, Dewey means a total response to what we meet: sensually, affectively and cognitively. In such a response, the world acquires meaning and we are conscious of what we experience; the present situation is understood in terms of both its actual qualities and its relation to former experiences. In the rhythm of everyday life, most of our experience is inchoate; we only become aware of what Dewey calls an experience in 'problematic' situations that are beyond implicit understanding. We are no longer part of an event or situation in a taken for granted way. We are conscious of a rupture. This need not be a shocking, dramatic event. We mostly experience it as being touched, a shiver, a deepening of emotion. An experience may be the result of exploring a work of art, listening to music, participating in a religious ritual or in any situation that holds a surprise for us.

In an attempt to restore harmony, we reflect upon the 'problematic' situation. This results in the discovery of new layers of meaning and the strengthening of the emotional appeal of the situation. An experience is characterized by an intense, vital feeling of being alive. Dewey describes this as the 'thrill' of the experience. We will easily remember such an experience because of its accompanying feelings of satisfaction and joy. It is difficult to express what happens in non-poetic ways. The hope to reach this intensity of experience is part of our anticipatory pleasure when visiting an exhibition or concert, reading a novel, watching a film or participating in a religious ceremony.

These examples make clear that an experience has aesthetic quality. The aesthetic experience is characterized by transcendence of the subject-object 
divide that is part of scientific research and of situations in which we control or manipulate our environment. Of course, the search for control cannot be totally relinquished. In our perception, we are always motivated by personal longings and needs. When these are dominant, we only perceive functionally in terms of the utility of an object in light of our own needs and aims. However, in the aesthetic experience we long for no more than what we perceive. 'The esthetic percipient is free from desire in the presence of a sunset, a cathedral, or a bouquet of flowers in the sense that his desires are fulfilled in the perception itself. He does not want the object for the sake of something else' (Dewey 1980: 254). Perceiving in this way is a form of participation in what we perceive, not only in a sensual but also in a 'senseful' way. We open ourselves to the intrinsic value of the 'other' and can become emotionally involved. The emotional colour of this experience renders it its unity and momentousness. The imagination plays a decisive role in this way of perceiving: it allows us to see the factual in light of the possible, thus enriching it with new layers of meaning. Imagination brings sensuous qualities, emotion and meaning together in an experience that may change our way of understanding the world.

\section{Imagination}

Dewey's approach is a strand in the broader field of process philosophy. He strongly opposes a subject-object dualism and categorizing people on the basis of statistics. In his view processes of transaction are the foundation of how people relate to their world. Human beings continuously face new challenges that ask for adequate responses. It makes no sense to study people as isolated individuals because of the strong interdependency with their environment. For this reason, Dewey prefers the term transaction instead of interaction that suggests a relation between two independent entities. The term 'transaction' makes clear that Dewey addresses the interconnectedness of person and world with all its changes and dynamics. In this process, human beings are not passively determined by their surroudings; they anticipate what will happen and adjust their responses accordingly. In this they are guided by their intelligence, understood as the abiltity to find solutions for problems in specific situations. Intelligence is not an abstract cognitive capacity, but develops through actual experiences in real life situations. This is a crucial element in Dewey's view on education.

The transaction between person and world gives rise to learning processes. People explore the best way of conduct in situations that further develop in relation to their responses. Memories of their discoveries are stored and result in dispositions to act in certain ways. Again, this is not primarily a cognitive process: our knowledge is embodied and expresses itself in the way we act. A strong metaphor is the dance: in an experience person and 
world are dance partners and the person responds out of embodied knowledge without distanced, cognitive deliberation. A ballet dancer need not think about her moves to enact them adequately; in the same way, we are able to use knowledge that 'lives' in our muscles. Still, our strong adaptability relies on symbolic operations that allow for virtual experiment. Next to the embodiment of knowledge, our symbolic capacity is of crucial importance in our learning processes. We need not learn through 'trial and error', because we are able to make mental images of the effect of a given course of action. We can prepare for a meeting by imagining what others will say and how they will respond to our statements. In this way, we can mentally experiment with actions without direct consequences in the physical and social world. People are not constrained by what factually occurs, but are able to imagine the potentials of a given situation. Imagination is a strong force in our learning abilities.

Imagination is not to be confused with non-committed phantasy. Imagination depends on attentive perception of the given situation to discover its possibilities. Dewey distinguishes between two interrelated aspects of the imagination: (1) taking the perspective of the other (empathy) and (2) creatively exploring the situation in its potentiality (creativity). Taking the perspective of the other allows me to open myself up to creative ways of looking at the situation I find myself in. Openness for creative ways of looking enhances my capacity to take the perspective of another person. In this way, empathy and creativity are closely connected, although this need not result in pro-social behaviour. I come back to that later. For now, it is important to realize that imagination does not lead to a pullback from the world we find ourselves in. Rather, it allows us to continually explore the possibilities for improving our situation.

What does this mean, 'improving our situation'? People long for a meaningful relationship with their environment. The world is not a neutral projection screen on which we can project our meanings. The world is wayward and unruly. It makes sense on its own terms. Creative though we may be in the ways we give meaning, we can never disconnect from a world that responds to our projections in affirming or rejecting ways. In the context of this unruly world we aspire to a 'good life'. According to the philosopher Thomas Alexander (2013) we are driven by a fundamental need for meaning and value directed towards the 'good'. I will elaborate on this in the section on religion. Here I want to stress that people always live in relations of interdependency and mutual response: not only with other people but with the world as a whole. The German sociologist Hartmut Rosa (2016) uses the term resonance when this interdependency results in meaningful experiences. The resonance that resounds in the transaction between person and world is not to be traced back to one of the partners. It depends on the rela- 
tionship and it enables us to find fulfillment in how we experience our world.

\section{Invitation and Resonance}

I want to address this idea of resonance within the context of the process approach of political philosopher William Connolly. According to him we need new ways of thinking about how humans relate to other forms of being. We live in a continuously changing world with a high level of complexity. New issues emerge which are impossible to predict from what went before. How do we cope with the creative forces that are at work on different levels in our world, ranging from a micro level of e.g. bacteria to a macro level of climate patterns? How can we deal with the constructive and destructive potentials of these forces? Connolly speaks of 'a world of becoming', in which we can participate as human beings to strengthen constructive potentials (acknowledgment) but to which we may also respond indifferently or even rejectingly. Crucial in how we respond to the world is our need for 'existential attachment' and a 'sense of belonging'. Fulfilling this need has never been easy and the era we live in today brings its specific challenges. One of these challenges is that we, as an individual, can choose between many different creeds and worldview positions, which gives all of them a sense of relativity and makes it hard to commit oneself to any of them. This undermines our belief in the world. Connolly stresses the importance of an explicit search for and dialogue about our existential sources of meaning and value. We are invited to participate in this ever-changing world and how we respond to this invitation does make a difference. He argues out of concern for societal problems like racism, social injustice and climate change. We have to collaborate to overcome these problems in ways that are motivated by a spiritual affinity that transcends our divisive creeds. Only by working together out of shared concerns and inspired by what we have in common, can we meet up to the huge challenges we are faced with in our time. To explore Connolly's view on invitation and spiritual affinity further, I make use of the concept of resonance as developed by Hartmut Rosa.

Earlier, I distinguished several ways of relating to our world: acknowledgment, indifference and rejection. In German, Rosa speaks of manners of Weltaneignung. Although this word suggests appropriation of the world or alternatively adjusting to it, Rosa does not mean control or one-sided assimilation. For him, an affirmative response is grounded in trust and love. It is characterized by openness for and commitment to what we meet, and by feelings of being supported and secure. Acknowledgment of life or of the world manifests itself in how we relate to other people, the spaces we move in, the tasks we take on us, the ideas we have or receive, the things and tools 
we work with. Usually we affirm parts of the world that we meet in specific situations. We are connected to these parts through what Rosa calls a 'vibrating thread', a connection of movement and being moved. We touch and set something in motion and at the same time we are touched and moved by the other. Such an experience of mutual acknowledgment empowers people in facing the challenges the world presents them with, giving them trust to cope with these challenges in constructive ways. In experiences of resonance, the world sounds splendid and colourful and we find our own voice in response. In Dewey's terms this is the core of an experience. Speaking each in their own voice, person and world touch and respond to each other. In total absence of this experience, for example due to clinical depression, the world is cold, empty, hostile, colourless and we ourselves are rigid, motionless, deaf, and mute. Instead of resonance we experience alienation; our relation to the world is 'dumb' and doesn't allow voices to be heard and brought to meaning.

In what way, we relate to the world depends on bodily, biographical, emotional, social and cultural factors. According to Rosa, worldviews (kognitiv-emotionale Weltrepräsentationen oder Weltbilder) are an important part of these cultural factors (Rosa 2016: 29). Worldviews can be 'world-opening' or 'world-closing': they can enhance our sensitivity for experiences of resonance or they can block these experiences. However, they never operate independently of the other factors mentioned. The biographical factor refers to personal experiences of a person resonating with (part of) the world, e.g. when falling in love. On the other hand, most people unavoidably experience moments of alienation. Without these painful experiences, we would not know the longing for resonance, for confirmation of the world and being confirmed. This longing results in strategies to find experiences of resonance and avoid alienation. These strategies determine our (implicit) images of the good life and the actions we take to strive for the good.

Rosa's view on resonance clarifies my idea of being invited in a world of becoming. An affirmative response weaves a 'vibrating thread' between me and that part of the world with which I resonate. Once more, I can use dance as a metaphor. Dance is a play of being invited, saying 'yes' to the invitation and surrendering myself to the movement. My partner and I áre the dance, the movement, the vibration; we shape the dance and are being shaped by each other. In Rosa's relational perspective self and world are shaped in their interdependence, but they don't echo each other. In their 'dance' each expresses its own voice and remains the 'other' in the relationship - a potential stranger. The metaphor of dance and voice points out the importance of the body in our relation to the world. From the very first inhalation, the world enters the infant in a literal way. Inhaling can be seen as an affirmative response to the world that invites the child to live. Converse- 
ly, to breathe is also an invitation to the world, that responds with providing vital oxygen. The infant's very first experiences with breathing can be confidence-inspiring or terrifying. If all goes well, the rhythm of our breathing is part of an ontological security (or basic trust) on which we build our relationship to the world.

However, responding to the world also means that we experience (bodily) boundaries. The world is not available and manageable in limitless ways and may offer resistance to what we try to accomplish. Resonance is not the same as consonance or harmony; that both self and other express their own voice implies the possibility of friction and contradiction. Resonance is the result of dialogical processes of adjustment, tuning and change that can result in deep feelings of connectedness and attachment. Friendship is a good example. We need not always agree with one another to experience friendship. Exploring our differences, tuning in to accomplish a shared task, changing because of our relationship can all enhance its intensity. The arts provide another good example of how resonance may result from relationships that confront us with rupture and friction. This example allows me to revisit Dewey's view on experience and imagination.

\section{Art}

Art is the quintessential domain in which people use their imagination and symbolic power to understand the world. Art is the domain of the possible; it explores the world behind or beyond what we usually accept as fact. Those facts are the result of habitual ways in which we cope with the world: we develop routines that allow us to act and move with ease. This is effective and enhances our security, but we also shield ourselves from full participation in the world we live in. Art, according to Dewey, helps us to see what we have come to overlook. It does so by breaking through our habitual ways of looking at the world; in this sense, all forms of art depend on friction with what we take for granted. In fact, everything that has this potential can be called art. It need not be Culture with a capital C. A coffee cup that draws our attention in such a way that we no longer sip our coffee thoughtlessly, manifests itself as a piece of art in that situation. We may look at it attentively, we may like its form and colour and in this way, it loses its insignificance as a functional object. It now has intrinsic value for us and we may remember it as something with its own presence or 'voice'. We have now entered a relationship of resonance that influences the way we treat this little object. Art helps us to (re)connect to our world.

Art in public spaces may confront us unexpectedly and impactfully. The Australian artist Guido van Helten paints people on public buildings, thus giving a 'face' to e.g. a house or viaduct. One of his paintings shows the face of an older person on the wall of a house in demolition in Ireland. I often 
use a picture of this wall with its painting and its surroundings to make my students aware of how they look at the world. Viewers of the picture see many different things: the face of a man or woman on the wall, the grey colours of the picture as a whole or the patches of blue in the sky, the sloppy looks of the surroundings or the green plants that are popping up in unexpected places. They learn that it is worthwhile to take time to look at a painting or another piece of art, and to explore it together with others, who look in different ways. Entering into dialogue with the work of art and with others, their imagination is stimulated. Students become aware of their associations derived from former experiences, knowledge, and cultural or religious frameworks. When we look at something, we attach meaning to it based on what we have learned about the world throughout life. In working with the picture of this painting by Guido van Helten, one viewer associated the face of the person on the wall with that of Christ. Immediately, another followed by associating the woodwork on the wall with a cross, and the patches of red paint with blood. For others, the associations were totally different, depending on what demolition, the face of an older person, the total atmosphere of the picture meant to them in the context of their biography. For all of them, however, the painting gave not only a face but also a voice to this ragged wall. Students felt invited to ask questions and to respond to the painted person they connected to.

Of course, we have to take our time and look attentively to enter into such a relationship. If we do, what is ordinary and commonplace (a house in demolition) may acquire emotional and perhaps spiritual value. Dewey stresses that in this way art may influence how we behave towards the world. It not only changes our way of looking, but also how we treat the other we meet. Of course, this is not always the case-I have often heard the counterargument that some Nazi's were sensitive artlovers. Still, I am convinced that without art our potential for experiencing and acting would be poorer. A book, a movie, a piece of music, a painting, can give a new perspective on life, and may invite us to change in small or more consequential ways. A picture, an image, a dance can open a world for us to which we want to relate affirmatively. Art-in Dewey's broad sense-can become a way of looking and a way of living, not restricted to the museum but available in daily life. Art enables us to relate to what goes beyond us, to transcend routine and meanings we take for granted. It invites us to reach beyond functional ways of relating and to weave 'vibrating threads' between ourselves and the other. Can we call this the religious potential of art?

\section{Religion}

John Dewey criticizes institutional religion because it diverts the commitment of people from this world to an absolute and transcendent Good, only 
to be reached by true believers who follow specific directives. Institutional religion may energize people, but this energy is needed for transformative action in our actual world. It is to this endeavour that Dewey dedicates his book A Common Faith (1934). It is not my aim to discuss his criticism of religion, which is of course highly influenced by time and context. Noteworthy is the positive potential this humanist thinker confers upon religion. This will be the focus of the present section.

Thanks to their imagination, people can make images of and aspire towards a 'good life'. Earlier, I spoke of our fundamental need for meaning and value directed towards the good. The images we make are no individual phantasies, but are rooted in social imaginaries shared within the culture we are part of. According to Dewey, the good we strive for is not something absolute-to be reached in a next life by believers-but something worthy that can be the aim of our collaboration. This is what religion is about. Religon, in Dewey's understanding, refers to a shared ideal stemming from social imaginaries of the good and pursued in collective action.

To aspire to the good is not without danger. Social imaginaries risk to influence both individual and social life in negative ways. Someone may pursue a self-destructive ideal, and a dictatorial regime may manipulate people's imagination in such a way that they are ready to take violent actions. Especially when power ties up with religion a potentially dangerous force may result. Such a play of forces can only be bridled in a democratic society, in which social imaginaries of the good are subject to critical reflection and can always be adjusted. This is a central message in A Common Faith. Dewey sees democracy as a way of aspiring to the good that is not restricted to the strictly political domain, but that extends to education and social life in a more general sense.

Relating Dewey's views to Connolly's and Rosa's thinking on invitation and response has implications for understanding religion. Pursuing the good life happens in a world that responds to this endeavour. We usually say that people give meaning to their world, but 'finding meaning' is equally important. People experience meaning when they are acknowledged by another or when they themselves can respond affirmatively to an invitation. In a nutshell, Dewey's view on religion is: saying 'yes' to the invitation to participate in a world of becoming, with implications for action in a shared aspiration to the good. His view might be too optimistic. In many situations, we do not feel invited and there are many things in the world we want to reject. In a pluralistic society, it can be hard to find an ideal shared with others, let alone to realize it in the commotion and tenacity of every day life. Dewey is fully aware of the restrictions we meet when pursuing the good and he is convinced that it is ultimately beyond our reach. The good will remain an imaginative idea, but one with a powerful appeal. It is the func- 
tion of religion to keep this idea alive and for this reason religion has lasting relevance in human existence. It should not lose itself in metaphysical abstractions, but it can become reality in people's experience. In Art as Experience Dewey discusses the religious quality of experiences against the background of his general theory of experience. He argues that any experience has religious potential, depending on its transformative power. He invites his readers to sensitize themselves to this aesthetical and religious potential of everyday life.

\section{Religious Experience}

According to Dewey an experience has religious power when it results in deeper, lasting commitments in life. He agrees with the criterion William James uses to recognize religious experiences: By their fruits ye shall know them, not by their roots' (James 1961: 34). Religious experiences are not as rare as is often thought. They occur in significant moments in life that evoke an awareness of supportive values in the person. It is an experience of integration, felt as a sense of inner harmony and harmony with our surroundings. After having experienced a break, for example because of an invasive life event, we now surrender to what heals us and restores a sense of wholeness.

The religious experience is rooted in the imagination. Far from being a flight from reality, imagination starts with paying close attention to the situation at hand to discover its potential. What possibilities for a good or better life, for healing and reintegration can be found within this situation? Imagination has a strong transformative potential. It may result in an experience of wholeness of the person and/or the world and in a sense of trust that something good can be realized. The religious experience opens us up to something of lasting value that contrasts with the fragmentary, fleeting moments of our daily existence. Dewey describes religious belief as unification of the self by committing oneself to an encompassing ideal or purpose, that is recognized as being worthy to guide ones needs and choices. Imagination evokes in us an ideal that touches and activates us. An ideal is no illusion; it is a force that affects our actions. From this perspective, the relationship between an aesthetic and a religious experience can be clarified. An aesthetic experience acquires religious quality when it evokes in us an ideal that guides our sense of self and world, thus giving unity to the fragmentary elements of everyday life.

People can have intense experiences of unity-Dewey expresses his own mystical experiences in his poems-but these do not refer to a supernatural reality and should not result in the passive feeling that unity has been reached already in another, transcendent realm. Religious experience is part of a never-ending process of unification and can stimulate people's en- 
deavours to realize their ideals in daily actions. In the midst of evil and suffering that confront people, they can imagine possibilities that have not yet been realized, but that still belong to the potentials of reality. This is the kernel of what religion is about. This deep, religious sense of destiny and commitment can only be reached in a transaction between the person and his or her environment. It is not the experience of an isolated individual, it is part of our entanglement with the world. We have no guarantees that our ideals are worth striving for, unless we discuss them with others and reflect their effects on the world around us (in its human or non-human forms). The source of religious belief is the human longing for the good life, but this is not an absolute given to be reached by the devout that hold on to religious prescriptions. It is something we can strive for in our daily actions, in which we may fail and in which we may advance by using our reflective and critical capacities.

Dewey's philosophy of religion tries to balance two aspects of the religious experience: the moral and the mystical aspects. Both aspects connect the religious to the aesthetical, that opens us up to the possibilities to be realized in this world as the input for ethical deliberation and that evokes feelings of harmony and commitment to a greater whole as part of a mystical experience. Dewey does not offer us a systematic account of the relationship between the religious and aesthetic dimensions of an experience, but it is clear that these are closely interwoven in his philosophy. Religious experiences are fulfilling and meaningful, as are aesthetic experiences. And the imagination as evoked by a work of art may give religious quality to an aesthetic experience, by presenting us with a uniting ideal or even an intense experience of unity and wholeness.

\section{Concluding Remarks}

Following the line of thinking of Dewey and Alexander, my point of departure for understanding art and religion as invitation is our fundamental longing for a life that is meaningful and has value. Due to our imagination, we are not limited to seeing things in their factualness, but we can explore their possibilities and aspire to what we conceive of as good. Artists have a talent for this exploration, and their expressions of imagination may help us to stimulate ours. They help us to look in new ways, find unexpected perspectives and pose critical questions by taken for granted sense-making. We can meet the world in its meaningfulness, and we open ourselves up to a resonance that may evoke a spiritual experience.

However, the world can be inviting, but also repelling or even hostile. It takes courage to say yes to a capricious world. This courage can be derived from religion, in its close connection to a shared ideal pursued in collective action. Our longing for meaning and value acquires a religious quality 
when we feel invited to contribute to the realization of a shared vision of the good. Such a vision is rooted in social imaginaries that feed cultural and religious traditions. Misleading as these social imaginaries can be, we need to articulate them in an imaginative process that allows for reflection and adjustment. In that case, imagination takes the form of a hermeneutical circle, starting with attentive perception of the present situation with its potential for meaning and value (attention). Our perception is never fully openminded: we draw on knowledge, former experience and cultural or worldview traditions to give meaning to a situation (association). However, we need not be restricted to limitative associative patterns when we dare to experiment with our perceptions and the associations they evoke. Ideally, others are involved in this experimentation to be able to understand the situation we find ourselves in from different perspectives. This may lead to adjusted visions of the good and the expectation of new courses for action (anticipation). Imagination, as understood here, is not complete without expressing such an anticipation in acting (expression) followed by critical reflection, again from several perspectives. Do our expressive actions meet what we had anticipated, can they do justice to the richness of the situation we attentively perceived, and what are the consequences of our actions for others involved? The 'cycle of imagination' (Alma 2018) is realized by this process of attention, association, experimentation, anticipation, expression and reflection-which calls for attentive perception.

This cycle can constitute the core of both a personal spirituality and a democratic process in which social imaginaries of the good are brought to expression and are reflected upon. Both in personal-spiritual and in collective-political aspirations, art and religion can play a pivotal role by nourishing our associations and anticipations and by providing us with new perspectives for experimentation and reflection. In their close relatedness, art may support religion to open itself to the cycle of imagination with its inescapable elements of experimentation and critical reflection, thus preventing it from becoming rigid. Art and religion may evoke intense experiences of togetherness and invite us to new ways of connecting. They may invite affirmative responses that weave a 'vibrating thread' between us and that part of the world with which we resonate, calling us to commit ourselves to and care for what we meet.

\section{Bibliography}

Alexander TM (2013) The human eros: Eco-ontology and the aesthetics of existence. New York: Fordham University Press.

Alma H (2018) De kunst van samenleven: Een pleidooi voor een pluralistisch humanisme. Brussel: VUB Press. 
Connolly WE (2011) A world of becoming. Durham \& London: Duke University Press.

Dewey J (1934) A common faith. New Haven: Yale University Press.

(1989) Art as experience, volume 10: The later works 1925-1953. Carbondale: Southern Illinois University Press. (Original work published 1934)

Rosa H (2016) Resonanz: Eine Soziologie der Weltbeziehung. Berlin: Suhrkamp.

Taylor C (1989) Sources of the self: The making of the modern identity. Cambridge: Cambridge University Press. 